\title{
Arabic Language and Computational Linguistics
}

\author{
Dr. Abdelhakeem Tawfeeq Issa \\ Department of Computer Sciences, Community College, Shaqra University-KSA
}

Dr. Ahmed Gumma Siddiek

Former Head/Dept.of English, Al-Zaeem Al-Azhari University-Sudan

College of Science \&n Humanities-Dawadai, Shaqra University - KSA

*Corresponding Author: Dr. Ahmed Gumma Siddiek, Former Head/Dept.of English, Al-Zaeem AlAzhari University -Sudan. College of Science \&n Humanities-Dawadai, Shaqra University - KSA.

\begin{abstract}
Arabic Language is lagging behind in the digital sphere. Many people believe that the problem is within the nature of Arabic in terms of letters and script. Some others hold different viewpoints; as they believe that many other languages such as Japanese, Chinese, Turkish, Hebrew have advanced Arabic in term of the digital content and made stronger presence of content on the Internet. There are many factors that should be investigated in order to determine the causes of weakness of the Arabic content on the Internet. Lack of scientific research in technical fields and the inability to produce and store knowledge by Arab information research centres may be the main factors behind this phenomenon that reflects the gap and poor digital content on the internet. Arabic is the fourth largest language in the world today, with more than 185 million users and it comes immediately after English, Chinese and Spanish. This is good news for Arabic supporters but great efforts are needed to close the digital gap of Arabic in the digital cyberspace.
\end{abstract}

Keywords: Arabic, digital divide, digital content, technology, language education.

\section{INTRODUCTION}

Language is the most distinctive human characteristic among all creatures. It is not just a system that generates sounds to convey meaning, but a mirror of the human mind. It is a vessel and vehicle of knowledge. Arabic is one of the oldest languages, characterized by novelty, vitality and flexibility. ${ }^{1}$ Since the advent of the computer in the late 1940s, its connection with language is getting closer and deeper. Language is at the top of the subjects of interest of the humanities. The computer is the culmination of modern technology, so it was logical, but crucial, for language and computer to meet. We cannot imagine the theoretical and practical benefits that we can get from the computer. As when we study language materials without the use of computers, it is necessary to use certain linguistic approaches. These linguistic approaches need to be stored in the human memory with limited characteristics, but many difficulties will result from the storage in this memory.

Thus, the computer memory can do a lot of boring things and many others that a person's memory cannot do, such as verb derivations and the tuning of its derivation paths. ${ }^{2}$ In this research, we tried to determine the degree of confidence among a very important sector of the society, namely, the community of workers in the field of higher education. The large proportion of them works in the fields of engineering, technology and computer are using Arabic, to transfer modern technology sciences to support Arabic in their fields of knowledge.

The first priority is to the feeling of pride with Arabic and the emotional attitudes towards this language. During the preparation of this study we asked some of our subjects about their opinions in the Arabic Language and how they feel towards it; "I am proud of Arabic because it is my mother tongue". Their response to this question was positive by more than 95\%." And when we investigated their degree of belief in the ability of Arabic to absorb modern scientific terminology in all technological fields; they believed that "Arabic has the ability to absorb modern scientific

عبدالعزيز المهيوبي , جهود اللغويين العرب الحاسوبية لخدمة الدراسات اللغوية العربية المحلات الصرفية العربة نموذجاً.

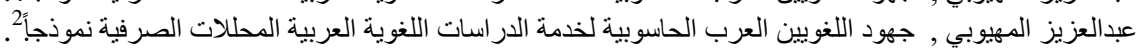


terminology in all technological fields". The response was positive by more than $92 \%$. So emotionally the question was settled with almost absolute confidence in Arabic and its ability to keep up with the new terminology of modern sciences.

\section{TWinning OF COMPUTER AND LANGUAGE OVER TIME}

Computer technologies have evolved over the years. It is difficult to determine the date of the beginning of the use of computers in the study of language in the world, because it happened at different times and different stages, and it was the result of various attempts in different countries. In the United States of America, computational Linguistics began in 1954 in the Department of Linguistics at Georgetown University, in the field of machine translation from other languages into English, as well; in some European countries also it began nearly the same time. ${ }^{3}$ In the Arab world, almost fourteen years after the advent of the computer, Egypt's National Planning Institute acquired an electronic computer. At first, it was limited to printing the Arabic script by replacing the English letters with Arabic letters.

From 1973 to 1985 , there were a number of important applications, including attempts to automatically generate Arabic speech, represented in some attempts developing processors with limited potential. But the second qualitative shift took place in mid-1985.

This was the first step at the level of the Arabic morpheme, as the first qualitative shift was dealing with letters (characters), due to the successful management of $\mathrm{R} \& \mathrm{D}$ section in Al Alamia that developed the first integrated multi-phase morphological analyzer. ${ }^{4}$ Thus began a serious phase to process mechanically Arabic morphology. ${ }^{5}$

There were many manifestations of information technology that served Arabic in the development of teaching and learning. So in the area of operating systems, the global operating systems such as MS DOS and Windows had been localized and modernized. In the area of application programs, several Arab programs emerged to coordinate to print Arabic texts by adding some Arabic and Islamic features to them. At the same time the Arabic fonts programs, spelling and grammatical programs, automatic reading programs of Arabic texts, automatic translation programs from and to Arabic, and multiple Arabic programs for learners and other speakers, witnessed some progress. ${ }^{6}$

\section{LANGUAGE TECHNOLOGY OR LINGUISTIC ENGINEERING}

Chomsky's transformational Grammar theory paved the way to the use of these formulations in the design of computer systems that dealt with the human language. Computer Professional scientists benefited from the formulations of language rules developed by linguists to use in computer application. Formal mathematical formulation was a prerequisite for building computer applications. Computational linguistics is the science of reunion between two sciences that may seem distant from each other, namely linguistics and computer science. Computational linguistics is the study of the computational aspects of language and the common problems facing computer processing of a language in its written or spoken form. Computational linguistics is also defined as the study of computer systems that try understanding, generating and analyzing natural languages. So computer linguistics is a special science naturally emerged from the advanced technological developments, where the theoretical and linguistic aspects of cognitive and methodological backgrounds met with the technological aspect of developments; to form together the computer linguistics or what is known as computational linguistics. It is a new science established by the collaboration of experts from both sides. So linguists alone cannot claim to have established this science as individuals nor can the computer scientists. The work in natural languages computing requires two kinds of knowledge: precise knowledge of the components of the linguistic system according to the latest theories and modern linguistic laws, and familiarity with computer knowledge related to the processing of natural languages, especially in software side. The idea of linking language and technology began in the midfifties and early sixties, when scientists began to develop automatic translation programs. They provided technological potentials to serve this virgin research field. Their efforts focused on building

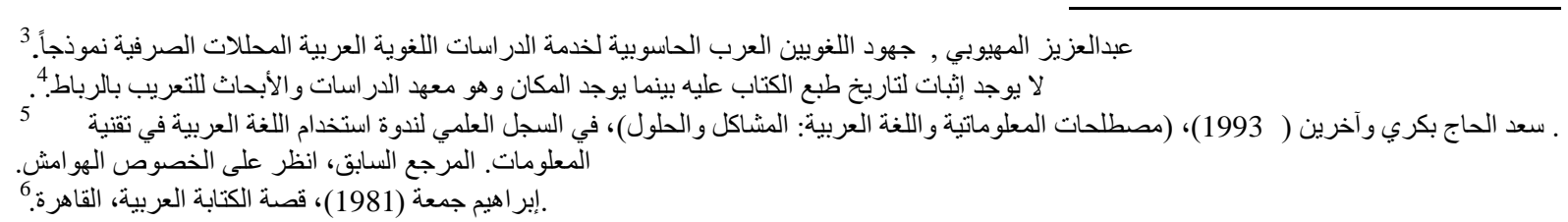


programming languages algorithms as well as adapting theories of artificial intelligence. These areas were intersecting with general linguistics in the way of dealing with the structure of natural languages. It was later found that linguistics employed the same tools used in machine translation to deal with a language, so the theme was common. This new field evolved into another name known as language technology or linguistic engineering.

\section{Contributions of Arab Researchers in Language TeChnology}

There were numerous researches and reform projects that focused on the Arabic letter in recent decades, as well as numerous conferences and debates held for the same purpose. ${ }^{7}$ The most important issue was how to insert and simplify the Arabic character by reducing the number of letters and processing the linking of letters in a single word. Perhaps one of the modest efforts of Arab computational linguists was the early book of Dr. Nabil Ali (Arabic and Computer), published in 1988. It was the first book that dealt with the subject of Arabic linguistic engineering at all levels. The linguistic aspect of Arabic according to Ali was important as appeared in his book "Arabic Language and Computer"; where he believed that the automation of morphology of Arabic was a basic entry and common denominator of most of automated systems. Ali also indicated the extent to which we succeed in localizing information and knowledge systems depending primarily on what we could achieve on the "morphological front". On the technical level, the processing of Arabic Morphology was an essential requirement for automating the analysis and understanding the written and spoken texts, as well as being an indispensable basis for the automation of dictionaries and the retrieval of information as well as text analysis. ${ }^{8}$ Ali's book was a successful step towards the establishment of Arab computational linguistics, both on theoretical and applied basis.

In 1998, Dr. Eid Diab Al-Ajili's published his book (Computer and the Arabic Language). This book was an attempt to deal with Arabic by using the basics of computer artificial intelligence. The author sought to lay the foundations for making communication between man and machine possible. In 2000, Dr. Nihad Al-Mousa published his book "Towards a New Characterization in the Light of Computer Linguistics". It was the first book about computer written by an Arabic specialist. It was an effective start in the syntax of the sentence in Arabic from a computational point of view. In 2007, "Computer and the Mechanization of the Arabic Language" was published by Rafat Al-Kamar.

It is noteworthy that these individualistic efforts were, but soon became multilateral, after being embraced by centers and technical institutes, computer societies in the Arab world and abroad, in addition to local international commercial institutions and companies. This was done following the revolution of informatics and the influx of knowledge in today's world.

This situation led to the feeling that all individuals and groups were facing a cultural challenge, against the deep pessimistic perceptions of the relationship between Arabic and computer, and thus this feeling developed linguistic and technological sense for the use of computers to serve the Arabic Linguistics. ${ }^{9}$ But despite the exerted efforts in the Arab research in characters; standardization did not take place quickly to keep pace with the requirements of information and electronic developments in the field of human knowledge. This was mainly due to poor coordination and poor cooperation among the Arab countries. The Arabic characters based on geometric logic; this fact was exploited by some commercial Western companies to find markets for their products. In our questionnaire we asked the participants that "Arabs are seriously adopting Arabization of modern sciences". The result showed that $81.5 \%$ o of the participants agreed to this, and what could apply to Arabization, consequently should apply to the transfer of technology or manufacturing technology in Arabic. In another question in the study, that says, "I am familiar with modern initiatives that support Arabic in science and technology." The result showed that $33 \%$ of participants were positive, while $07 \%$ were much surer about that. So the Initiatives are still weak. The question will still remain whether the technical problem is so complex that it could not be tackled, or there is a room to build and establish position for Arabic in computer and technology fields; then consequently booking a place for Arabic in the cyberspace in this third millennium.

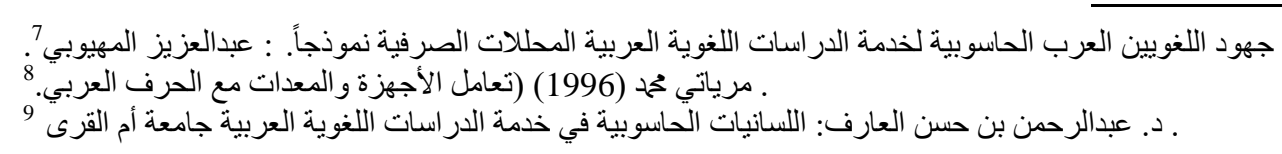




\section{Arabic Content And the Digital Divide}

There is a lot of talk about the relationship of languages and the digital divide. Despite the language impact; there are other factors that affect the digital divide, including the accumulation and production of knowledge and the rapid technological progress. The digital divide is the distance between the owners and non-owners of knowledge at the quantitative and qualitative levels, and then how to benefit from this knowledge and work on its development ${ }^{10}$. The extrapolation of Arabic relationship with the digital divide reflects a terrible unacceptable backwardness, considering that Arabic is the sixth largest language in the world in terms of speakers. It is a universal language adopted by the United Nations in its international applications. (95 million) people use the Internet in the Arab world, while the percentage of Arabic content on the Internet is less than 1\% compared to Dutch speakers. whose number does not exceed 20 million, or Turkish, Polish and Italian. This means weakness of presenting Arabic in the digital arena. ${ }^{11}$ (see figures below).

\section{Top Ten Languages in the Internet 2013 - in millions of users}

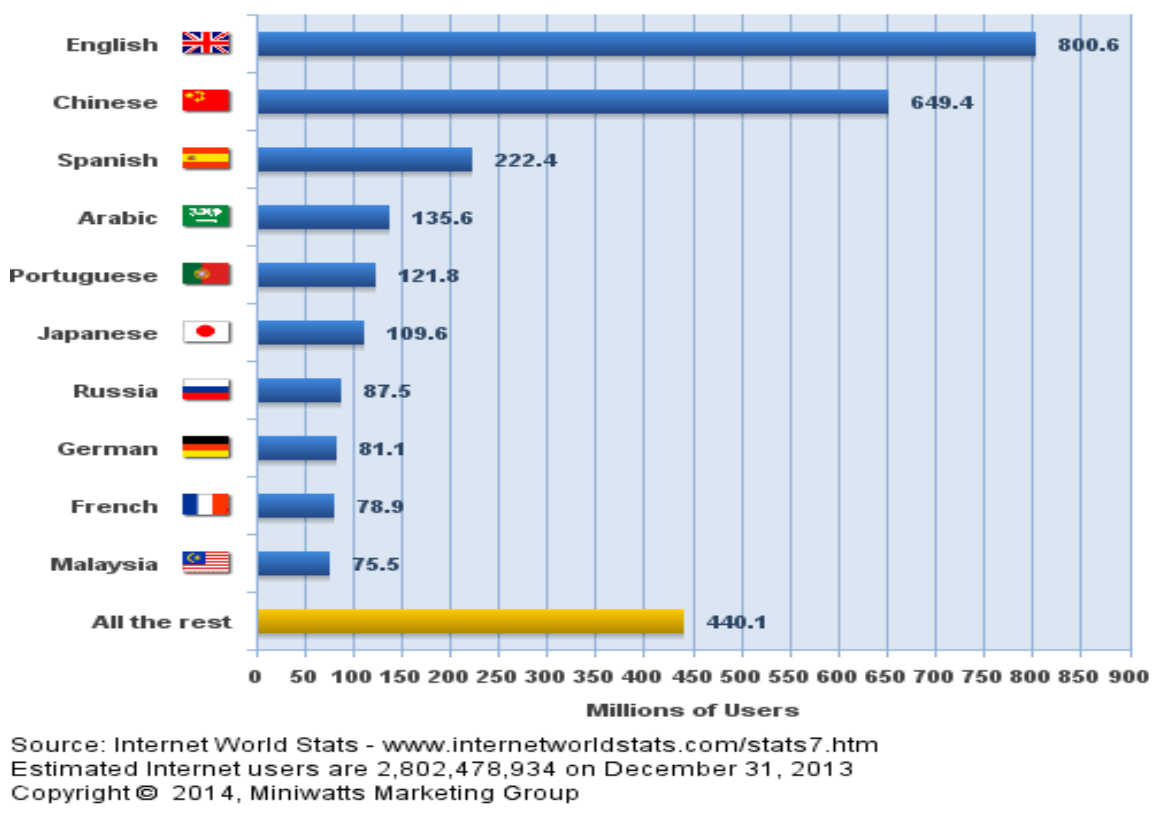

But the question is still: Why is Arabic lagging behind in the digital spheres? Many people believe that the problem is within the nature of Arabic in terms of its letters and script, while others do not see this as evidence because other foreign languages, such as Japanese, Chinese, Turkish, Hebrew, etc... advance Arabic in term of the digital content and have stronger presence of content on the Internet. There are a number of factors that should be investigated in order to determine the causes of weakness of the Arabic content on the Internet. It is not easy to fully cover these factors of this deterioration but they may be due to cultural and scientific reason. The Arab educational institutions bear the largest part of the responsibilities. Poor Arabic education is one direct cause of weakness of Arabic among students, in addition to the invasion of foreign languages against Arab culture in institutions of higher education. Lack of scientific research and the inability to produce and store knowledge in the Arab world by information research centers are additional shameful phenomena that reflect the extent of Arab backwardness in the digital divide when compared with developed countries.

So if you happened to browse the Arabic content on the Internet you may definitely notice the weakness of the Arabic content. There is huge repetition and plagiarism of other people's work. We can also notice a degree of triviality of the transmitted information, in addition to serious errors in scientific translation from foreign languages into Arabic. And concerning translation of foreign terms on the Arabic digital pages, we can notice that many of these translations use incorrect terminology based on non scientific approaches. The terms are not standardized; therefore there is a lot of disagreement over them from one country to another in the Arabic region. Surprisingly, the Arabic

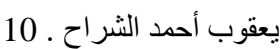

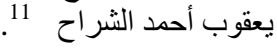


terminology on the Internet is written in colloquial language. This will pave the way for the spread of foreign words to spoil the classical Arabic, and will consequently increase the gap of disagreement and cause chaos in scientific terms. Unfortunately, this looks natural since the Arabs disagreement on terminology is not far from their political differences ${ }^{12}$.

\section{Cyberspace and E-Learning in the Service of Arabic}

For the success of e-learning by using Arabic as medium of instructions, we have to update the curriculum to keep up with the age of modernity, as well as developing teachers'e-learning abilities to enable learners acquire basic Arabic skills to serve this new informatics society. This will enable us to confront the open world and the revolution of technology with a conscious mind, to develop and qualify ourselves for the challenges of modernity and creativity, as well as mastering the computer culture in our own language.

Therefore, we need to prepare Arabic for the demands of the information age, and inject fresh blood in this great language theoretically and practically by using it as medium of education in all sciences. This can only be achieved by teaching our young people to technically think in Arabic to understand the close relationship between programming and thought on one hand and the language on the other hand. There are fruitful efforts to address Arabic automatically. Therefore, when designing programs in e-learning; attention should be paid to the linguistic content in context rather than purely linguistic context. This will undoubtedly enrich the student's general information and improve their linguistic achievements, as well as helping them to develop in their subjects matter. Attention must also be given to the development of computer programs that develop the needs of Arab learners regardless of their level of language proficiency, while taking into consideration the presentation of content in fluent Arabic and intensifying efforts to promote the development of Arabic in e-learning. This can all be done by feeling proud of Arabic language and its heritage and by intensifying teaching in general education, in addition to directing users of Arabic to the importance of electronic dictionaries. We need to make great efforts to book our place in the digital sphere that is mounting to nearly 4 billion people using the internet toady. (see figures below)

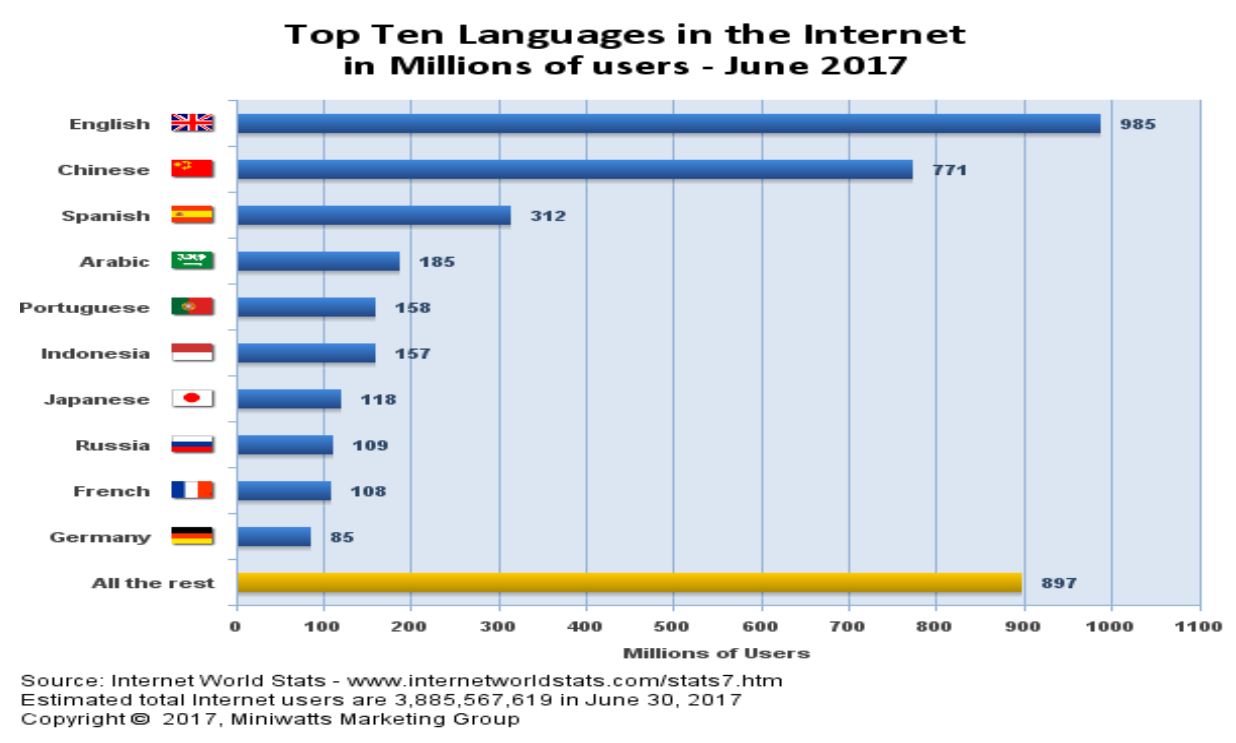

Researchers and specialists in education should facilitate Arabic education, so that computer specialists can establish and design educational programs, similar to the practice in other sciences. The cooperation between computer technicians, linguists and educators will contribute to produce educational programs that can help to attain goals and make e-learning successful in all dimensions. We also need to encourage teachers to use Arabic in teaching and learning modern sciences in order to Arabize terminology in these fields.

Hence, it will be possible to say that the real benefit of e-learning technology and the resulting science and knowledge will benefit the Arab world through the Arabization of this technology and its resettlement and other people in the world as well. There wouldn't be a paradigm shift for science and

يعقوب أحمد الثراح 12 . 
technology in the Arab world, if we have not dealt with this age of information from an Arab perspective to cover the practical needs of every member in the Arab nation. This can only take place within a disciplined unified language because language in informatics society is at the forefront. Today's communication technologies require Arab countries to establish networks at sectoral, national or regional levels, but the interest of Arab countries in building these networks unfortunately remains limited. Bu the Gulf network can stand as a good example of the technical capabilities available in this field; the same can be said about the Arab Industrial Information Network and the OIC Network.

However, Arabic communication services are still poor. This is a good reflection of how this language can be used in networks and digital applications. It also reflects standardization in related applications. In this regard, there is a need to undertake multiple efforts in this field, not least of which is to initiate officials at decision level to feel the importance of developing communications services in Arabic. It is also necessary to allocate intellectual and material resources that would help pushing these services to keep abreast of developments, as well as participating in international organizations working towards standardization; we also need to push these organizations to take the requirements of Arabic with its unique nature into account in the international standards.

\section{LANGUAGES, TRANSLATION AND TERMINOLOGY}

The explosion of the media, which is truly a characteristic of this twentieth century, resulted in an explosion in the number of terminologies, including scientific and technical terms. For example, the number of terms created each year in English is approximately 9,000 terms and the French is around 2000. An important percentage of this figure estimated at $80 \%$ is for technical vocabulary including computers, electronics and information networks. ${ }^{13}$ This raises the problem of finding the equivalent for these terms in Arabic. This also illustrates the effort that separates us from keeping pace with the developments in this framework. There is no doubt that addressing terminology cannot occur in isolation from the language issues; as it reflects the level of progress/backwardness experienced by the language speakers and the language maintainers. This reality raises multiple objective and subjective problems, as well. Objectively speaking, languages and the means available to formulate the new terms are numerous. In terms of languages, English is the language of terminology production due to its control of 80 and $85 \%$ of scientific and technical terms in all fields. Transferring of terminologies into English takes place from other languages, including French, Spanish, etc., and these languages may in turn be conveyors or translators of these terms from other languages. This raises, among other things, the problematic nature of determining which language should we translate from? Shouldn't we at least be obliged to translate from the original language of the terminology?

The multiplicity of available means to formulate the term, and the multiplicity of centers of Arabization interested in Arabization of the term in the Arab world, as well as the number of scholars and linguists who are interested in the subject, in addition to the intervention of the identities due to regionalism, which no Arabic country is void of, and the lack of systematic studies, in addition to the absence of binding plans and the poor coordination... all of these factors mentioned above resulted in a fragmentation of efforts and a multiplicity ${ }^{14}$ in the number of equivalents for one specific foreign terms, and also added lack of respect for the other terms used by other countries ${ }^{15}$. The multiplicity of means to formulate the term slows down the emergence of terminology to cope with the frequent developments, as well as delaying recognition and adoption of these terms by Arab countries at official level and at public or private life. Banks of Computer Terminologies may be good beginning of joint actions by Arab countries, similar to the efforts exerted by the Francophone, German and Russian terminology banks. This was done in addition to the works of the International Center for Terms (INFOTERM) in Vienna, which have been coordinating the efforts of those banks to exceed the political boundaries and to operate these banks in a clear language. The sole concern of this center is to renew dictionaries to face the steady increase in the number of terms in informatics and electronics. But the prevailing view among experts will remain that the Arab efforts in the field of

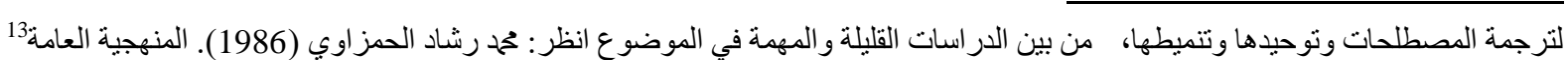

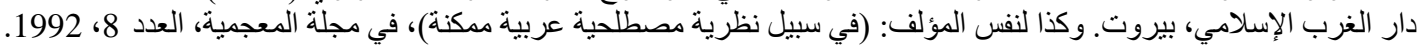

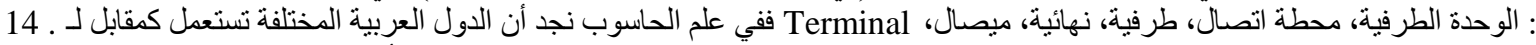

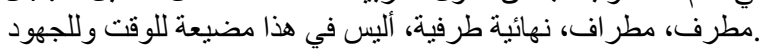

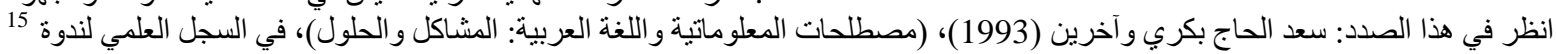

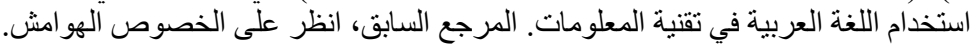


computer terminology are insufficient to achieve the desired interaction between the Arabic language on one hand, and the progress in the field of technology on the other.

According to our study we have found passion and readiness of participants towards Arabic, at the same time, we have come to see researchers and scholars severely suffer from the lack of Arabic Digital Content in addition to the weakness of terminology and translation in the relevant literature. The table below can reflect the way Arab users think about the situation of Arabic in the digital cyber spheres.

\begin{tabular}{|l|l|l|}
\hline No & \multicolumn{1}{|c|}{ statement } & \multicolumn{1}{|c|}{$\%$} \\
\hline 1 & I find specialized content in Arabic available and appropriate. & $37 \%$ \\
\hline 2 & I have the ability to understand modern scientific terminology in Arabic. & $63 \%$ \\
\hline 3 & In order to keep up with my new specialty, I have to study English & $100 \%$ \\
\hline 4 & Arabic is able to adapt to modern technology. & $85 \%$ \\
\hline 5 & $\begin{array}{l}\text { I encourage the Arabization of scientific terminology in all fields of modern technology into } \\
\text { Arabic. }\end{array}$ & $85 \%$ \\
\hline 6 & Arabization of modern scientific terminology is still weak and chaotic. & $81 \%$ \\
\hline 7 & I find authorship in Arabic suitable in terms of the use of scientific terms. & $37 \%$ \\
\hline 8 & I find everything I look for in my field of specialization in Arabic on the internet. & $18 \%$ \\
\hline 9 & I am willing to contribute to Arabization to transfer what I can in my field. & $70 \%$ \\
\hline 10 & I believe Arabic is not capable to transfer modern science. & $7 \%$ \\
\hline
\end{tabular}

\section{ARABIC AND TECHNOLOGICAL TERMINOLOGY}

In the light of the recent technological developments that have affected the world around us, Arabic had clear share of positive influence. One of the advantages of modern technology has provided Arabic with a range of tools and electronic applications that have preserved the idea of teaching Arabic structure with correct grammar and spelling ${ }^{16}$.

But the negative impact on Arabic was of direct effect. It led to mixing between spoken Arabic and the written English. This diglossia led to the emergence of a new strange hybrid language used in chat sites that is spreading more widely due to the spread of social networking sites. Unfortunately, a big number of young people have been affected by the technological problems which in turn affected Arabic. So Arabic is becoming weak because of many young users in schools and universities as well. Some of these people have adopted mixing Arabic words with foreign words to appear as if they are update with technological developments, but this behavior led to incorrect pronunciation and incorrect spelling of Arabic words over time. The weak performance in Arabic, in these days, is due to absence of pride in our language, as most of us show great affection to speakers of other foreign languages rather than feeling positive to our own mother tongue.

The sound thinking in this modern reality in the case of Arabic and its connection to technological progress makes it imperative for the Arab person to be keen about all means to support the positive impact of modern technology-which is a supporting factor in the maintenance of Arabic. Then everyone has to work to avoid falling into using negative applications of technology that continues to emerge everyday with many successive developments

\section{The Arabic Digital Content ON THE InTERnET}

It is not acceptable or reasonable to always flog ourselves and underestimate our language. Among the statistics that indicate the shift in the Arab digital capabilities is the latest classification adopted by the Internet World Stat for the first half of 2017. The global trends indicate that Arabic is the fourth largest language in the world now with more than 185 million users. Arabic comes immediately after English, Chinese and Spanish. This is good news for Arabic lovers and supporters. So while these figures seem normal for the first three ranks due to the widespread spread of English, the large number of Chinese-speaking populations and the continental extension of the Spanish; the classification of Arabic in the fourth place comes as a surprise to many followers of this classification. Comparing the figures of 2000, 2013 and 2017, the rate of growth of Arabic users on the network, during that period, was extremely high. In 2000, the number of Internet Arabic users was only 2.5 million. The continuing of this upward growth trend and the development will lead to Arabic to join the club membership of the dominant languages. (See the figures below)

مجد مالك خضر, اللغة العربية و التكنولوجيا.16 


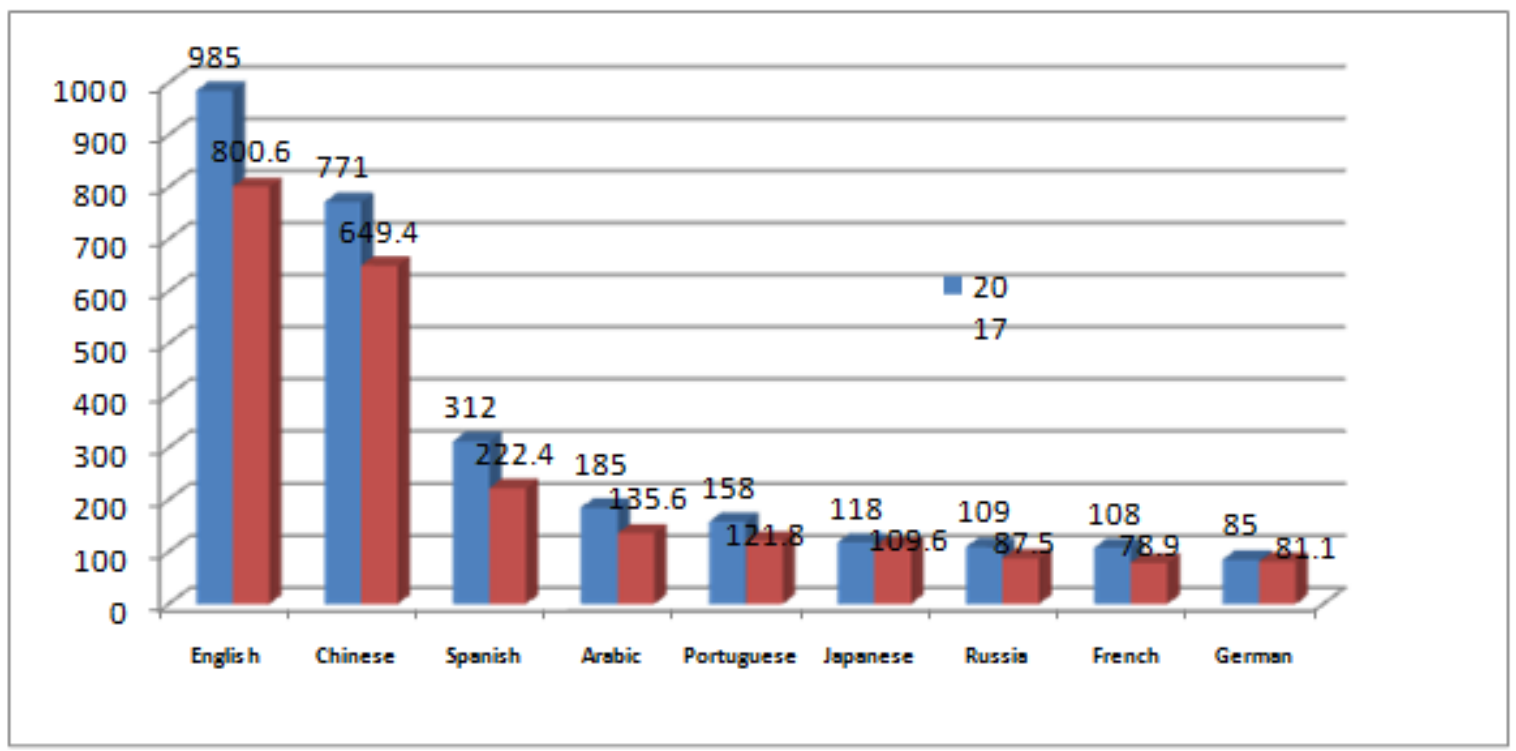

Source: www.internetworld stats.com/stats7.html.

\section{Advantages of Building Web Sites to Serve Arabic}

Talking about the Internet and its multiple uses in learning and teaching, in databases and its importance in facilitating scientific research benefiting the service of Arabic and the development of its teaching, is clear and uncontroversial. Some of these advantages can be mentioned as following:

1. To keep abreast with the technical development and prove Arabic flexibility in dealing with modern technologies.

2. Strengthening individual and institutional efforts aimed at serving Arabic and disseminating this language learning and teaching.

3. Making Arabic a global language by ranking it among the living languages and to be effective and influential in human development.

4. Disseminating more knowledge and expertise of Arabic, to make it available to researchers and scholars.

5. Removing geographical boundaries (restrictions) for those who pursue a common goal and wish to share their experiences.

6. Reviewing previous research and studies to avoid duplication.

7. Exchanging information related to field experiences, effective teaching strategies and research results.

8. Facilitating joint cooperation in the areas of development between teams and specialized committees in the field of teaching Arabic.

In response to one of our survey questions, we have asked participants if "[they] see an opportunity in the Internet sites to support Arabic.". The result showed that $77 \%$ of the participants agreed to this statement. This reflects the confidence that Arabic is capable to adapt to the changes, considering that publishing and promoting on the Internet is a good opportunity.

\section{TEACHING COMPUTER SCIENCES IN ARABIC}

The time spent by an Arab student in translation and attempting to learn in English over years can be seen as a knowledge base for learning terminology of computer science in English and can enable him/her to easily read computer books written in English. But what would happen if the student did not know English at all? And what would happen if the sources of information were only available in Arabic? And if students were not obliged to spend time learning another language? The direct impact on students learning computer science in the mother tongue would make them able to:

1. Learn Computer Science In Less Time.

2. Think Of Technology In Arabic, Where Ideas Grow From The Depth 
3. Able To Expand Knowledge And Knowledge By Reading Many References.

4. Able To Publish And Share This Science Simply For Everyone.

5. Able To Innovate With More Creativity.

\section{Are you Able to Translate to localize Computer Science?}

If you are able to make an impact on Arabization of computer science, or make an impact on your Arab nation do not hesitate as you can:

1. Professionally Translate A Book.

2. Write And Publish Books In Areas Where Arab Sources Are Rare

3. Participate In Projects Of Translation To Localize Computer Science.

4. Establish Projects Related To The Translation And Localization Of Computer Science

5. Contribute To Arabic By Effectively Publishing On The Web And Multimedia Sites

6. Contribute To Improve Translation Of Web Translators Such As Google Translator.

The Arab Center for Cultural Development and the European Lebanese Foundation (Actel) organized a cultural symposium entitled "Towards the Enhancement of Arabic in the Modernity of Information and Globalization". This is an (example) of efforts where the conference recommended the importance of Arabic in this era of information and globalization. The Center asserted that the preservation of any language is preservation of identity, culture, heritage and thoughts to preserve the future. The speakers at the symposium stressed that what we need today is to call on a linguistic security forces to maintain Arabic by adopting a comprehensive Arab Renaissance plan, that all educational institutions should give Arabic real care because these institutions are natural incubators of knowledge and builders of minds. The symposium also presented a number of proposals. The most important were the expansion of Arabic in all disciplines; by developing materials for teaching Arabic terms in every field of specialization taught in foreign languages. This will encourage students to attach a summary in Arabic to their scientific research published in foreign languages. We need to make the best use of educational technology to effectively and professionally teach Arabic.

When we asked our participants, if they believe that the weakness of Arabic is a natural reflection of the reality of the Arab nation political status. $74 \%$ of the subjects believe that this is true. In another question, "I believe that the advancement of Arabic is important for the renaissance of the Arab nation." This time $92.5 \%$ of the subjects believe that is also true, and $89 \%$ of the participants think that it is possible to return Arabic back as a language of advanced thinking as it had once been. This may bring some hope for Arabic speakers. Finally, if the Arab nation wants a comprehensive renaissance, it is necessary to start by focusing on their language, not disdaining it, but working to raise the technological level through the implementation of Arabic in all walks of life, with real sense of pride. Arabs need to understand the nature of these modern times in which knowledge of technology is no longer a luxury but a practical need for the individual person as well as crucial need for the development of any nation.

\section{REFERENCES}

[1] Al-Hamzawi, Mohammed Rashad(1986). Almanhajiayia Alaamah Li Tarjamt Almustalahat wa Tawheedaha wa Tanmeetaha. Dar AlGhrab Alislami,Beuirut. Laenbnon.

[2] Al-Khateeb, Ahmed shafeeq (1996). Almowasafat Al-Mostalhiya wa Tatbigataha Fi Al-Ghuh Al-Arabiah. The Arab Organization of Education, Cultural and Science. Tunis

[3] Almohalilat Al sarfiyah Namozagan. http://www.m-a arabia.com/vb/showthread.php?t=7193. Retreived October 2018

[4] Al-Qurrashi, A.Aziz Al mahyoubi (2014). Al-lugha Alarabiah fi Asr Almaalomatiyah.: Juhood Alughawiin Ararab Alhassobiyah Li Khidamat Adrassat Allughawiyah Alarabiah, Alsharah, Yagoub Ahmed (2011). Alugha Alarabiyia wa Alinternet.

[5] Bakri, Saad Alhajj (et.el 1993). Mustalaht Almaalomatiyah wa Al-algugha Alarabia:Almashakil wa Alholol. Seminar of Using Arabic Language in Informatics Technology, Fourth Conference, Tunis

[6] Gumaa, Ibrahim (1981). Gisat Al-Kitabah Al-Arabiah. Cairo, Egypt. 
[7] Helial, Mohammed Hilmi (1996). Altagiyees Almostalahi fi Albilad Alarabia: Fi Alughaha alarabia wa Tahdit Alqarn 21. The Arab Organization of Education, Culture and Science. Tunis. http://www. alraimedia.com/Home/Details?Id=51142fe1-3933-44c1-936e- faf83b52b25d. Retrieved October 2017

[8] Khider, Majjd Malik (2017). Alughaha Alarabiah wa Teknologia.: wasail Altwasoul Alijtmaie wa doraha fi Tadahwor Istikhdam Alughah alarabia.

[9] Mohammed,Meryatti (1996). Taamul Alijhezah wa Almoaadat maa Al;ahraf Alarabi. The Arab Organization of Education, Cultural and Science, Tunis

\section{AUTHOR's BIOGRAPHY}

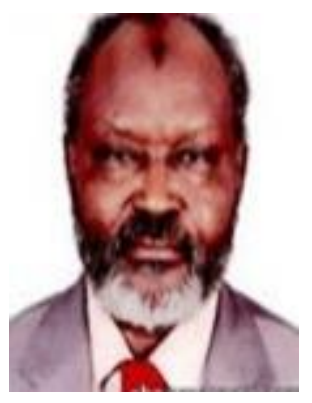

Dr. Ahmed Gumaa Siddiek, got his B.A in English with (MERIT) from Khartoum University in (1982). He has an MA in Translation from the Islamic Institute for Translation in Khartoum as well as an M.Ed in (TEFL) from Juba University-Sudan (2002). He got his Ph.D with (EXCELLENT) in (Language Testing) in (2004) from Omdurman Islamic University-Sudan. Since then Dr. Siddiek has been lecturing in Sudan and Saudi Arabia. He has published widely in ELT journals in USA, UK, Canada, Finland, Australia and India. He attended conferences and read papers in Harvard and Purdue, in USA. His papers were also accepted for conferences in Germany, France and Canada. Dr. Siddiek is the Author of: (Assessment of the Sudan School Certificate English Examinations) \& (Language Challenges in Post-War Sudan). He is a member of many editorial Boards of ELT journals in Canada, USA and Australia.

Citation: Dr. Ahmed Gumaa Siddiek "Arabic Language and Computational Linguistics". International Journal on Studies in English Language and Literature (IJSELL), vol 6, no.11, November2018, pp. 4-13. doi:http://dx.doi.org/10.20431/2347-3134.0611002.

Copyright: (C) 2018 Authors. This is an open-access article distributed under the terms of the Creative Commons Attribution License, which permits unrestricted use, distribution, and reproduction in any medium, provided the original author and source are credited. 